\title{
Atmospheric Environmental Capacities of Jingjinji and the Five Northwestern Provinces and Autonomous Regions in China
}

\author{
Hao Jiming ${ }^{1,2}$, Xu Jiayu ${ }^{1,2}$, Wu Jian ${ }^{1}$, Ma Qiao ${ }^{1}$ \\ 1. School of Environment, Tsinghua University, Beijing 100084, China \\ 2. State Environmental Protection Key Laboratory of Sources and Control of Air Pollution Complex, Beijing 100084, China
}

\begin{abstract}
This article takes the Beijing-Tianjin-Hebei (Jingjinji) region and five northwestern provinces and autonomous regions in China as examples to discusses the regional atmospheric environmental capacity of areas in different stages of economic development. The atmospheric environmental capacities for sulfur dioxide $\left(\mathrm{SO}_{2}\right)$, nitrogen oxides $\left(\mathrm{NO}_{x}\right)$, primary fine particulate matter $\left(\mathrm{PM}_{2.5}\right)$, volatile organic compounds (VOCs), and ammonia $\left(\mathrm{NH}_{3}\right)$ emissions were calculated for the various provinces with the constraints of the annual average ambient $\mathrm{PM}_{2.5}$ concentration standard (GB3095-2012), using a global atmospheric chemistry transport model from the Goddard Earth Observing System (GEOS-Chem). The results indicate that the total emissions of $\mathrm{SO}_{2}, \mathrm{NO}_{x}$, primary $\mathrm{PM}_{2.5}, \mathrm{VOCs}_{\text {, }}$ and $\mathrm{NH}_{3}$ emitted from Jingjinji and the five northwestern provinces and autonomous regions all exceed the environmental capacity.
\end{abstract}

Keywords: $\mathrm{PM}_{2.5}$; air quality; environmental capacity

\section{Introduction}

The huge energy consumption scale and energy consumption structure associated with coal as the main energy source in China cause the emission of a number of air pollutants. In recent years, large-ranging and lost-lasting fog and haze weather events have occurred in many regions throughout China. This has become a focus of attention in our society. To solve serious atmospheric pollution problems quickly and improve the ambient air quality, the State Council of the People's Republic of China issued and implemented the Air Pollution Prevention and Control Action Plan in September 2013. Since the action plan was implemented in 2013, the annual average concentration of $\mathrm{PM}_{2.5}$ in 74 cities of China has been lowered. However, the annual average concentration of $\mathrm{PM}_{10}$ in seven provinces of China increases. $\mathrm{PM}_{2.5}$ and $\mathrm{O}_{3}$ pollution in Eastern China is serious. We still face huge challenges regarding ambient air quality in China, as a whole, and in key regions of China.
Atmospheric environmental capacity refers to the maximum allowable emissions of air pollutants in one region under the constraint of a certain environmental target (such as ambient air quality compliance or critical load for acid deposition). In actual studies, we pay more attention to "regional atmospheric environmental capacity," which refers to the allowable total amount of pollutants, in certain regions, that are emitted from various pollution sources to the atmosphere per unit time under certain weather conditions and pollution source emission conditions and on the condition that the ambient air quality target in the region is met. Besides environmental chemical characteristics of air pollutants, factors affecting the atmospheric environmental capacity include regional environmental target, regional geographic characteristics, and weather characteristics.

In China, atmospheric environmental capacity always is used as an important basis of total amount control of air pollutants and air quality control. Regarding atmospheric environmental

Received date: June 20, 2017; Revised date: July 10, 2017

Corresponding author: Xu Jiayu, School of Environment, Tsinghua University, Senior Engineer. Major research fields include energy utilization and atmospheric pollution simulation and control policy. E-mail: jiayu-xu@tsinghua.edu.cn.

Funding program: CAE Advisory Project “Several Strategic Issues on Eco-Civilization Construction (Phase II)" (2015-ZD-16)

Chinese version: Strategic Study of CAE 2017, 19 (4): 013-019

Cited item: Hao Jiming et al. Atmospheric Environmental Capacities of Jingjinji and the Five Northwestern Provinces and Autonomous Regions in China. Strategic Study of CAE, https://doi.org/10.15302/J-SSCAE-2017.04.003 
capacity under various environmental targets, Chinese scholars have carried out much study. The Ambient Air Quality Standard of China was revised in 2012. $\mathrm{PM}_{2.5}$ became the primary pollutant affecting ambient air quality compliance in our cities. Compared to $\mathrm{SO}_{2}, \mathrm{NO}_{2}$, and $\mathrm{PM}_{10}$, the limit value of $\mathrm{PM}_{2.5}$ in ambient air is stricter. Therefore, based on the need of air quality management in China, the atmospheric environmental capacity as per $\mathrm{PM}_{2.5}$ compliance must be calculated, to provide scientific basis for air pollutant emission reduction [1]. Study of atmospheric environmental capacity in the Jingjinji region and five northwestern provinces of China will provide an important basis for establishing a precise fog and haze prevention and control system for regions at different stages of economic development.

\section{Study method}

\subsection{Overview}

In the study, 2013 was used as the base year and 2030 as the target year. The atmospheric environmental capacities for $\mathrm{SO}_{2}$, $\mathrm{NO}_{x}$, primary $\mathrm{PM}_{2.5}, \mathrm{VOCs}$, and $\mathrm{NH}_{3}$ emissions in the Jingjinji region and five northwestern provinces were confirmed by using the global atmospheric transmission model GEOS-Chem to conduct analog computation of pollutant concentrations in ambient air owing to the emissions from air pollution sources and based on the constraint condition that the annual grid average concentration of $\mathrm{PM}_{2.5}$ in the Jingjinji region and five northwestern provinces in 2030 meets the Ambient Air Quality Standard (GB3095-2012), so as to analyze the overload condition and emission reduction need in the base year.

\subsection{GEOS-Chem model setting}

(1) Simulation period: entire base year (2013) and entire target year (2030). The simulation interval is $3 \mathrm{~h}$.

(2) Simulation area: China and other Asian regions close to China, extending to Japan in the east, India in the west, Siberia in the north, and Indonesia in the south. The longitude and latitude ranges were $70^{\circ} \mathrm{E}-150{ }^{\circ} \mathrm{E}$ and $11^{\circ} \mathrm{S}-55^{\circ} \mathrm{N}$, respectively, and the grid resolution was $0.5^{\circ} \times 0.667^{\circ}[2]$.
(3) Emission inventory: For artificial source emissions of the base year and target year in China, the latest artificial source emission inventory of Tsinghua University was used [3]. The default emission inventory of GEOS-Chem was used for other conditions.

(4) Selection of meteorological year: the GEOS-5 meteorological field used was updated to 2012 in 2015 . Based on the comparison result between emissions of the base year 2013 simulated using the meteorological data of 2010-2012 and monthly average concentration of $\mathrm{PM}_{2.5}$ in Eastern China, the monthly average concentration of 2012 in Eastern China mostly approached the monthly average concentration of three years (2010-2012) $\left(6.28 \mu \mathrm{g} \cdot \mathrm{m}^{-3}\right)$. The monthly average concentrations of 2010 and 2011 were $25.94 \mu \mathrm{g} \cdot \mathrm{m}^{-3}$ and $-32.22 \mu \mathrm{g} \cdot \mathrm{m}^{-3}$, respectively. Therefore, the year 2012 was used as the meteorological year.

\subsection{Model verification}

While using GEOS-Chem to calculate the atmospheric environmental capacity, the meteorological field, emission inventory, and concentration field shall be verified.

Because the meteorological field for GEOS-Chem is an assimilative GEOS-5 meteorological field, verification of the meteorological field was not conducted in this study.

2.3.1 Comparison and check of emission inventory of the base year

The emission inventory of the base year was compared to other emission inventories of recent years in the study (Table 1). The emission inventories of Liu et al. [4], Xia et al. [5], and Wu et al. [6] were prepared using a bottom-up approach, and the 2015 emission data in Zhao et al. [7] was future predicted data based on the base year 2010. Unless the emission data issued by the Ministry of Environmental Protection is obviously lower than that in the emission inventories used in the study, the emission inventories used in the study are in the variation range of the study. One reason for the low emission data issued by the Ministry of Environmental Protection is that the emissions from non-road-traffic sources is excluded.

Table 1. Comparison between emission inventories and other recent studies.

\begin{tabular}{|c|c|c|c|c|c|}
\hline Item & $\mathrm{SO}_{2}$ & $\mathrm{NO}_{x}$ & $\mathrm{PM}_{10}$ & $\mathrm{PM}_{2.5}$ & VOCs \\
\hline This study & 23150 & 25638 & 16521 & 12155 & 23366 \\
\hline Ministry of Environmental Protection, 2014 & 20439 & 22273 & - & - & - \\
\hline Liu et al. [4], 2016 & - & 28300 & - & - & - \\
\hline Xia et al. [5], 2016 & $23014-26884$ & $28002-28817$ & - & - & - \\
\hline Wu et al. [6], $2016(2012)^{*}$ & - & - & - & - & 29850 \\
\hline Zhao et al. [7], $2013(2015)^{*}$ & 26792 & 27511 & 15599 & 11419 & - \\
\hline
\end{tabular}

*The year in parentheses indicates the year of emission inventory prepared in the study. 
2.3.2 Verification of simulated concentration of $\mathrm{PM}_{2.5}$ of the base year

Only if the simulated concentration of ground $\mathrm{PM}_{2.5}$ of the base year is correct, can the reliability of the simulated results in the future be ensured. In section 3.2.1, verification of the simulated concentration of $\mathrm{PM}_{2.5}$ of the base year will be discussed.

\section{Main results and analysis}

\subsection{Emission inventory of future years}

Atmospheric pollution is closely related to energy utilization. Emissions of the main atmospheric pollutants in future years depend on energy consumption as well as the control technology and countermeasures for atmospheric pollution. Emissions of the main atmospheric pollutants in future years are generally determined via the scenario analysis of different energy consumption scenarios and atmospheric pollutant control scenarios. This study is based on the research results of Zhao et al. [8]; it only analyzes the energy scenario (2030PC) and pollution control scenario (2030PC2) that can achieve the 2030 air quality target, as shown in Table 2 and Table 3, respectively.

The energy scenario is up to 2030, and compared to 2013, the energy consumption in China has increased by $7 \%$. Coal is still the largest proportion of the energy structure but has reduced from $61 \%$ in 2013 to $44 \%$. The percentage of renewable sources and nuclear energy has increased from $8.3 \%$ in 2013 to $15.1 \%$ in 2030 . For end control policies, the table lists two endemission control policies for each energy scenario. The distribution ratio of end control technology is mainly calculated based on the relevant government notice and planning. 2030PC2 is set up based on the Air Pollution Prevention and Control Action Plan, assuming the control measures will become stricter gradually through year 2030. In the scenario, flue gas desulfurization (FGD) devices are extensively used in power plants and industrial sectors, and newly built industrial boilers are required to install low $\mathrm{NO}_{x}$ burners (LNB). Electrostatic precipitators (ESPs) and high efficiency dusters (HEDs) will gradually replace the inefficient wet scrubbers (WETs). In civil sectors, the utilization rate of low-sulfur coal will reach $100 \%$ in 2030; more advanced coals and biomass stoves also will be widely used. For traffic departments, high emission vehicles will soon be eliminated and nearly $100 \%$ of the vehicles in 2030 will reach the current strictest emission standard in Europe [9].

\subsection{Analysis of atmospheric $\mathbf{P M}_{2.5}$ concentration in future years}

Taking 2012 as the meteorological year, with the pollutant emission inventory of domestic artificial sources in 2013 updated

Table 2. Key parameters of the energy scenario in 2030.

\begin{tabular}{|c|c|c|}
\hline Item & 2013 & $2030 \mathrm{PC}$ \\
\hline GDP (calculated as per the constant price in 2005) (trillion yuan) & 39.5 & 117.8 \\
\hline Population $\left(\times 10^{8}\right)$ & 13.6 & 14.7 \\
\hline Urbanization (\%) & 53.7 & 63 \\
\hline Generating capacity $(\mathrm{TW} \cdot \mathrm{h})$ & 5398 & 8000 \\
\hline Percentage of coal-fired power generation (\%) & 66.4 & 41.3 \\
\hline Crude steel production (Mt) & 779 & 570 \\
\hline Cement production (Mt) & 2417 & 1751 \\
\hline Urban per capita living space $\left(\mathrm{m}^{2}\right)$ & 23 & 29 \\
\hline Rural per capita living space $\left(\mathrm{m}^{2}\right)$ & 37 & 39 \\
\hline Motor vehicle number per 1000 people & 93.6 & 325.2 \\
\hline Percentage of renewable energy sources $(\%)$ & 8.3 & 15.1 \\
\hline
\end{tabular}

Table 3. Future scenario settings for 2030.

\begin{tabular}{|c|c|c|c|}
\hline Energy scenario & Scenario description & Emission scenario & Scenario description \\
\hline PC scenario & $\begin{array}{l}\text { In accordance with the promotion of new energy } \\
\text { saving policy and stricter implementation: } \\
\text { Increase of energy demand (including high } \\
\text { energy consumption industrial products, } \\
\text { construction area and housing service demands, } \\
\text { motor vehicles, generating capacity, and } \\
\text { heating) slows down owing to more energy- } \\
\text { efficient lifestyles; promoting clean and } \\
\text { renewable energy sources, and technology that } \\
\text { improves energy efficiency. }\end{array}$ & $2030 \mathrm{PC} 2$ & $\begin{array}{l}\text { Implementation of the Air Pollution Prevention and } \\
\text { Control Action Plan; control policies and measures will } \\
\text { be stricter in } 2030\end{array}$ \\
\hline
\end{tabular}


to the emission inventory of the future year and the emission inventory of natural sources and overseas sources remaining the same, the GEOS-Chem was used to simulate the ground distribution of $\mathrm{PM}_{2.5}$ concentration in the Jingjinji region and five northwestern provinces, as shown in Fig. 1. For easy analysis, in addition to the $\mathrm{PM}_{2.5}$ concentration variation in 2030, the monitored and simulated concentrations of said provinces and autonomous regions in 2013 were added. Furthermore, as only 74 cities had complete and continuous $\mathrm{PM}_{2.5}$ monitoring data by the end of 2013 [10] and only the provincial capitals of the said five provinces and autonomous regions were included, the $\mathrm{PM}_{2.5}$ ground monitoring data for 2015 were used in Fig. 1 [11].

\subsubsection{Verification of simulation values of ground $\mathrm{PM}_{2.5}$ concentration}

The ground $\mathrm{PM}_{2.5}$ concentration simulated by the GEOSChem model was verified via three parameters — standard mean deviation, standard mean error, and the correlation coefficient $\mathrm{R}$. The monitored data of ground $\mathrm{PM}_{2.5}$ concentration of the 13 cities in the Jingjinji region and the five capitals of the five provinces and autonomous regions was compared to the simulated concentration of the GEOS-Chem model grid located in the center of that city, and the results are shown in Table 4.

The standard mean deviation of the Jingjinji region is $-8.0 \%$, and the correlation coefficient $R$ is 0.83 ; the standard mean deviation of the five northwestern provinces is $-8.4 \%$, and the correlation coefficient $R$ is 0.97 . The model underestimated the ground $\mathrm{PM}_{2.5}$ concentration. This is because the meteorological year is 2012 and it is widely believed that the diffusion conditions in 2013 were better than in 2012, causing the results of the ground $\mathrm{PM}_{2.5}$ concentration simulated by the model to be slightly lower than the monitored data. Additionally, there are 66 cities in the Jingjinji region and five northwestern provinces, and the correlation analysis results between the monitored value

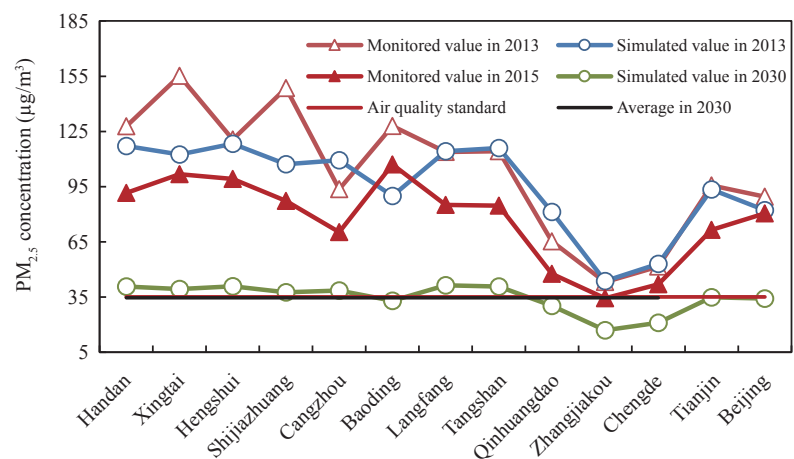

(a) Jingjinji region

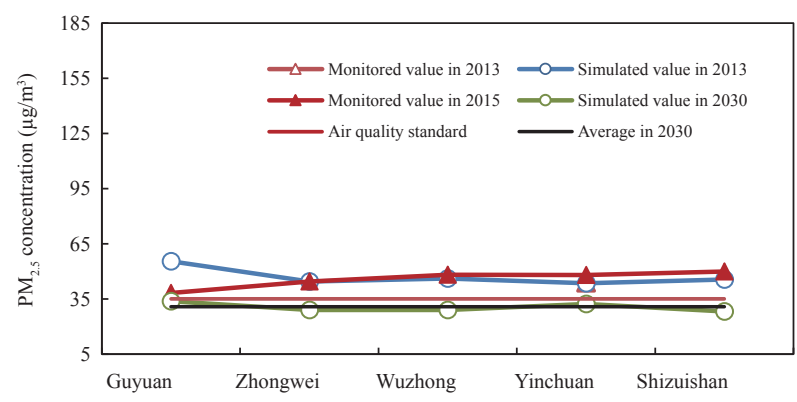

(c) Ningxia Hui Autonomous Region

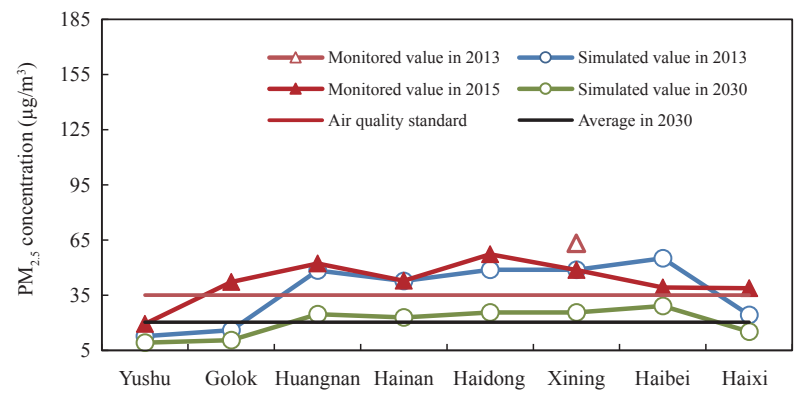

(e) Qinghai Province

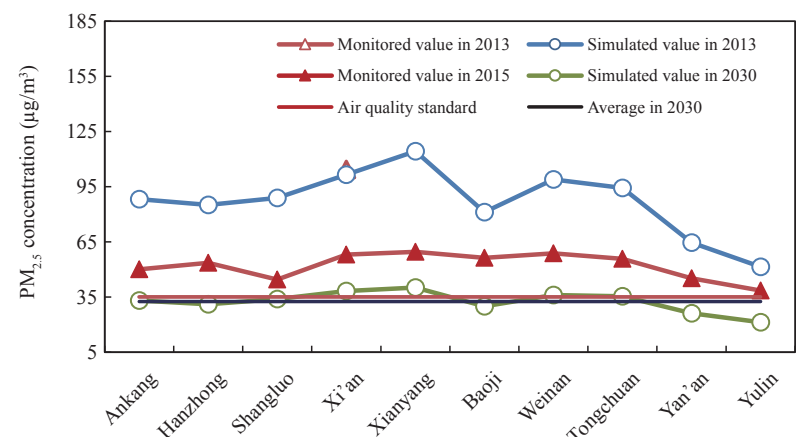

(b) Shaanxi Province

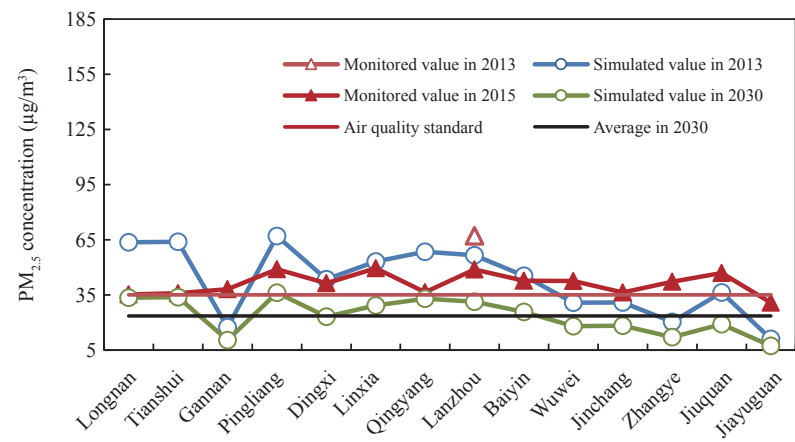

(d) Gansu Province

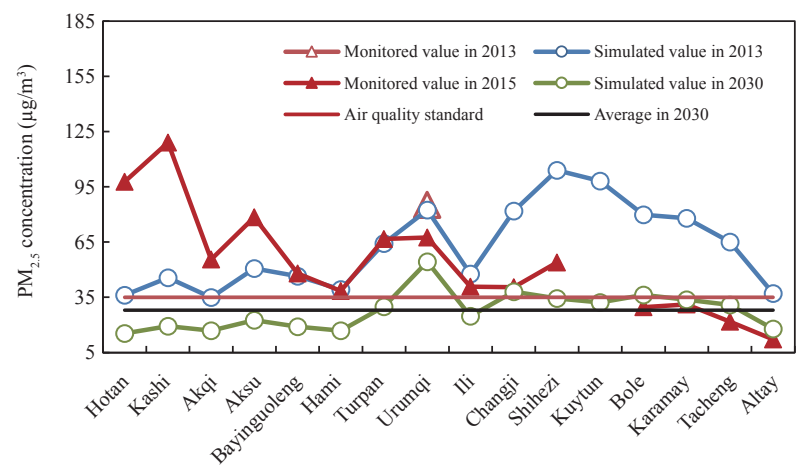

(f) Xinjiang Uygur Autonomous Region

Fig. 1. Ground $\mathrm{PM}_{2.5}$ variation in the Jingjinji region and five northwestern provinces. The abscissa has the cities sequenced from left to right with increasing latitude. 
of ground $\mathrm{PM}_{2.5}$ in 2015 and the simulated value in the base year are shown in Table 4. Although there are differences between 2013 and 2015 regarding both the meteorological field and emission inventory, the correlation analysis results can reflect the accuracy of the simulated results. The results indicate that the simulated results of the Jingjinji region, Shaanxi Province, and Qinghai Province were better than those of Gansu, Xinjiang, and Ningxia.

3.2.2 Analysis of ground $\mathrm{PM}_{2.5}$ concentration compliance in the future year

It is shown in Fig. 1 that the mean annual concentration of ground $\mathrm{PM}_{2.5}$ of municipalities and provinces in the Jingjinji region and five northwestern provinces can all achieve the Class 2 air quality standard $-35 \mu \mathrm{g} \cdot \mathrm{m}^{-3}$; however, 15 prefecture-level cities, out of 64, in Hebei Province and the five northwestern provinces cannot reach the standard. This means that the emissions in the emission inventory of the future year is the atmospheric environment capacity constrained by the annual mean concentration of $\mathrm{PM}_{2.5}$ of the grids in the Jingjinji region and five northwestern provinces reaching the ambient air quality standard (GB3095-2012), not the atmospheric environment capacity constrained by the annual mean concentration of $\mathrm{PM}_{2.5}$ of the grids in prefecture-level cities reaching the ambient air quality standard (GB3095-2012). The latter is less than the former, and the specific values of the latter should be determined in future research.

\subsection{Analysis of atmospheric environment capacity}

\subsubsection{Atmospheric environment capacity}

The emissions in the emission inventory of the future year is the atmospheric environment capacity constrained by the annual mean concentration of $\mathrm{PM}_{2.5}$ of the grids in municipalities and provinces in the Jingjinji region and five northwestern provinces reaching the ambient air quality standard (GB3095-2012). The environment capacities of $\mathrm{SO}_{2}, \mathrm{NO}_{x}$, primary $\mathrm{PM}_{2.5}$, VOCs, and $\mathrm{NH}_{3}$ are shown in Table 5 .

\subsubsection{Overload rate of atmospheric environment capacity}

The ratio between the atmospheric pollutant emissions and environment capacity in the base year 2013 was used to measure the atmospheric environment overload, of which the results are shown in Table 6. It is clear that the total overload of the five northwestern provinces was similar to that of the Jinginji region. The overload rates of primary $\mathrm{PM}_{2.5}$ and $\mathrm{NO}_{x}$ were $158 \%-400 \%$ more serious than the other pollutants. If we want to avoid atmospheric environment overload, the emissions of $\mathrm{SO}_{2}, \mathrm{NO}_{x}$, primary $\mathrm{PM}_{2.5}$, and VOCs in all regions should be reduced by $30 \%-75 \%$ relative to those in 2013 . The maximum reduction ratio of $\mathrm{NH}_{3}$ emissions was $53 \%$.

\section{Conclusions}

(1) Under the constraints of the annual mean concentration of $\mathrm{PM}_{2.5}$ of the grids in municipalities and provinces in the Jingjinji region and five northwestern provinces reaching the ambient air quality standard (GB3095-2012), the environment capacities of the five atmospheric pollutants, $\mathrm{SO}_{2}, \mathrm{NO}_{x}$, primary $\mathrm{PM}_{2.5}$, VOCs, and $\mathrm{NH}_{3}$, were respectively $609 \mathrm{kt}, 745 \mathrm{kt}, 295 \mathrm{kt}, 1322 \mathrm{kt}$, and $6260 \mathrm{kt}$ and those in the five northwestern provinces were respectively 926 kt, 947 kt, 349 kt, 758 kt, and 9160 kt. However, the compliance rate of the annual mean concentration of $\mathrm{PM}_{2.5}$

Table 4. Verification results of the simulated values of ground $\mathrm{PM}_{2.5}$ concentration in the base year.

\begin{tabular}{|c|c|c|c|c|c|c|}
\hline Item & Jingjinji region & Shaanxi & Ningxia & Gansu & Qinghai & Xinjiang \\
\hline Standard mean deviation (compared to 2013) & $-8.0 \%$ & & & $-8.4 \%$ & & \\
\hline Standard mean error (compared to 2013) & $13.4 \%$ & & & $8.2 \%$ & & \\
\hline Correlation coefficient $R$ (compared to 2013) & 0.83 & & & 0.97 & & \\
\hline Correlation coefficient $R$ (compared to 2015) & 0.80 & 0.85 & -0.85 & 0.32 & 0.68 & -0.20 \\
\hline
\end{tabular}

Table 5. Environment capacity of the main atmospheric pollutants.

\begin{tabular}{|c|c|c|c|c|c|}
\hline Region & $\mathrm{SO}_{2}$ & $\mathrm{NO}_{x}$ & $\mathrm{PM}_{2.5}$ & VOCs & $\mathrm{NH}_{3}$ \\
\hline Beijing & 5 & 7 & 2 & 24 & 40 \\
\hline Tianjin & 12 & 12 & 4 & 23 & 21 \\
\hline Hebei & 44 & 55 & 23 & 85 & 565 \\
\hline Jingjinji region & 61 & 74 & 29 & 132 & 626 \\
\hline Shaanxi & 32 & 23 & 9 & 29 & 268 \\
\hline Gansu & 16 & 21 & 8 & 16 & 234 \\
\hline Qinghai & 3 & 5 & 2 & 4 & 80 \\
\hline Ningxia & 12 & 12 & 4 & 5 & 40 \\
\hline Xinjiang & 31 & 33 & 12 & 23 & 294 \\
\hline Five northwestern provinces & 94 & 94 & 35 & 77 & 916 \\
\hline
\end{tabular}


Table 6. Overload of main atmospheric pollutants in the base year.

\begin{tabular}{|c|c|c|c|c|c|}
\hline Region & $\mathrm{SO}_{2}$ & $\mathrm{NO}_{x}$ & $\mathrm{PM}_{2.5}$ & VOCs & $\mathrm{NH}_{3}$ \\
\hline Beijing & 240 & 257 & 300 & 146 & 148 \\
\hline Tianjin & 200 & 283 & 275 & 139 & 213 \\
\hline Hebei & 227 & 275 & 378 & 174 & 169 \\
\hline Jingjinji region & 223 & 274 & 359 & 163 & 170 \\
\hline Shaanxi & 228 & 291 & 400 & 190 & 150 \\
\hline Gansu & 175 & 176 & 275 & 169 & 107 \\
\hline Qinghai & 200 & 240 & 300 & 150 & 100 \\
\hline Ningxia & 175 & 158 & 225 & 180 & 100 \\
\hline Xinjiang & 300 & 258 & 233 & 165 & 136 \\
\hline Five northwestern provinces & 235 & 234 & 289 & 175 & 128 \\
\hline
\end{tabular}

for 66 prefecture-level cities in the Jingjinji region and five northwestern provinces corresponding to the said environment capacities was $76.6 \%$, and the atmospheric environment capacity corresponding to the $100 \%$ compliance rate should be less than those capacities.

(2) The emissions of the five atmospheric pollutants $\left(\mathrm{SO}_{2}\right.$, $\mathrm{NO}_{x}$, primary $\mathrm{PM}_{2.5}, \mathrm{VOCs}$, and $\mathrm{NH}_{3}$ ) in the Jingjinji region in 2013 were respectively 2.23 times, 2.74 times, 3.59 times, 1.63 times, and 1.70 times its atmospheric environment capacity and those in the five northwestern provinces were respectively 2.28 times, 2.27 times, 2.81 times, 1.73 times, and 1.28 times its atmospheric environment capacity. The overloads of atmospheric environment capacity between the Jingjinji region and the five northwestern provinces in 2013 were generally the same. Therefore, during the implementation of the Belt and Road Initiative, attention should be paid to the constraints of atmospheric environment capacity of arid zones in western China. If we want to avoid atmospheric environment overload, relative to 2013, the emissions of the five atmospheric pollutants $\left(\mathrm{SO}_{2}, \mathrm{NO}_{x}\right.$, primary $\mathrm{PM}_{2.5}$, VOCs, and $\mathrm{NH}_{3}$ ) in the Jingjinji region should be respectively reduced by $55 \%, 64 \%, 72 \%, 39 \%$, and $41 \%$ and those in the five northwestern provinces should be respectively reduced by $56 \%, 56 \%, 64 \%, 42 \%$, and $22 \%$.

(3) The uncertainty of atmospheric environment capacity was determined via the air quality model, meteorological field, emission inventory, air quality standard, and other factors when utilizing the air quality model. This study used the GEOS-Chem model and the emission inventory of artificial sources in 2013 prepared by Tsinghua University and determined that the simulated values of ground $\mathrm{PM}_{2.5}$ concentration in Gansu, Xinjiang, and Ningxia provinces are negatively correlated or have low correlations with the monitored values. Therefore, it was confirmed through this study that the uncertainty of the atmospheric environment capacities of these three provinces is higher than that of the Jingjinji region and Shaanxi and Qinghai provinces, indicating the requirement for further studies.

\section{References}

[1] Xue W B, Fu F, Wan J N, et al. Modeling study on atmospheric environmental capacity of major pollutants constrained by PM2.5 compliance of Chinese cities [J]. China Environmental Science, 2014, 34(10): 2490-2496. Chinese.

[2] Chen D, Wang Y X, McElroy M B, et al. Regional CO pollution in China simulated by high-resolution nested-grid GEOS-Chem model [J]. Atmospheric Chemistry and Physics, 2009, 9(11): 3825-3839.

[3] Ma Q, Cai S, Wang S, et al. Impacts of coal burning on ambient PM2.5 pollution in China [J]. Atmospheric Chemistry and Physics, 2017, 17(7): 4477-4491.

[4] Liu F, Zhang Q, Zheng B, et al. Recent reduction in NOx emissions over China: synthesis of satellite observations and emission inventories [J]. Environmental Research Letters, 2016, 11(11): 114002.

[5] Xia Y, Zhao Y, Nielsen C P. Benefits of China's efforts in gaseous pollutant control indicated by the bottom-up emissions and satellite observations 2000-2014 [J]. Atmospheric Environment, 2016, 136: 43-53.

[6] Wu R, Bo Y, Li J, et al. Method to establish the emission inventory of anthropogenic volatile organic compounds in China and its application in the period 2008-2012 [J]. Atmospheric Environment, 2016, 127: 244-254.

[7] Zhao B, Wang S, Wang J, et al. Impact of national $\mathrm{NO} x$ and $\mathrm{SO} 2$ control policies on particulate matter pollution in China [J]. Atmospheric Environment, 2013a, 77: 453-463.

[8] Zhao B, Wang S X, Liu H, et al. $\mathrm{NO}_{x}$ emissions in China: historical trends and future perspectives [J]. Atmospheric Chemistry and Physics, 2013, 13(19): 9869-9897.

[9] Wang S X, Zhao B, Cai S Y, et al. Emission trends and mitigation options for air pollutants in East Asia [J]. Atmospheric Chemistry and Physics, 2014, 14(13): 6571-6603

[10] International Organization for Environmental Protection: Greenpeace. PM2.5 ranking of 74 cities in China, 2013 [EB/OL]. (201402-27) [2017-04-09]. http://www.greenpeace.org.cn/PM25-ranking. Chinese.

[11] International Organization for Environmental Protection: Greenpeace. PM2.5 ranking of 366 cities in China, 2015 [EB/OL]. (2016-01-20) [2017-04-15]. http://www.greenpeace.org.cn/pm25city-ranking-2015. Chinese. 